\title{
Mathematical modeling of the growth of ellipsoidal crystals in metastable melts and solutions
}

\author{
Margarita Nikishina ${ }^{1}$ and Dmitri Alexandrov ${ }^{1}$ \\ ${ }^{1}$ Ural Federal University named after the first President of Russia B N Yeltsin
}

September 30, 2020

\begin{abstract}
The evolution of individual crystals of ellipsoidal shape in supercooled one-component and binary melts as well as in supersaturated solutions is studied theoretically. The crystal volume growth rate is derived using the prolate ellipsoidal coordinates. We show that this rate is a function of the current crystal volume and supercooling/supersaturation of the ambient liquid. Also, we demonstrate that the particle growth rate increases with increasing the volume of ellipsoidal crystals and supercooling.
\end{abstract}

\section{Hosted file}

wileyNJD-DM.pdf available at https://authorea.com/users/363183/articles/484041-mathematicalmodeling-of-the-growth-of-ellipsoidal-crystals-in-metastable-melts-and-solutions 


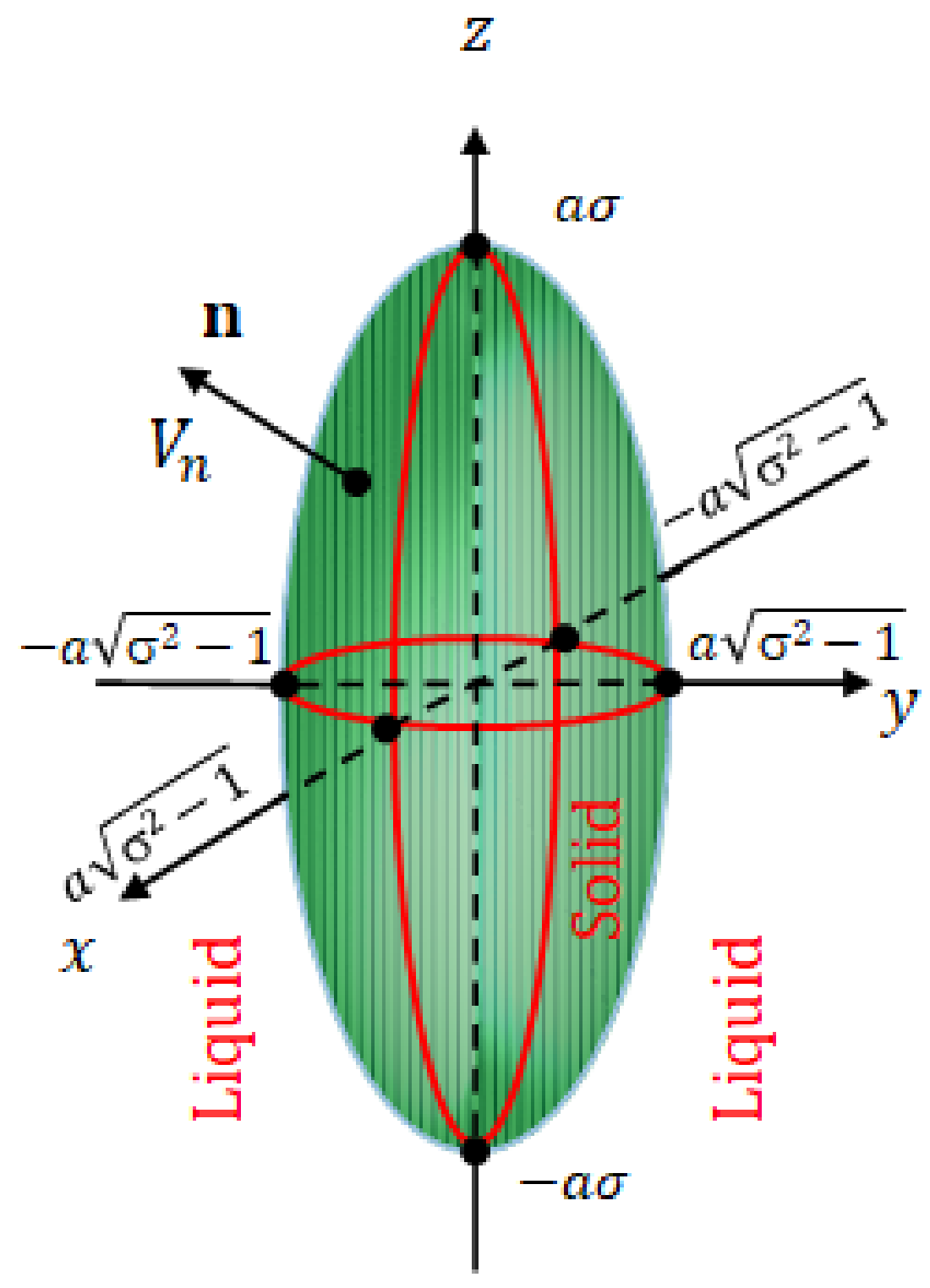



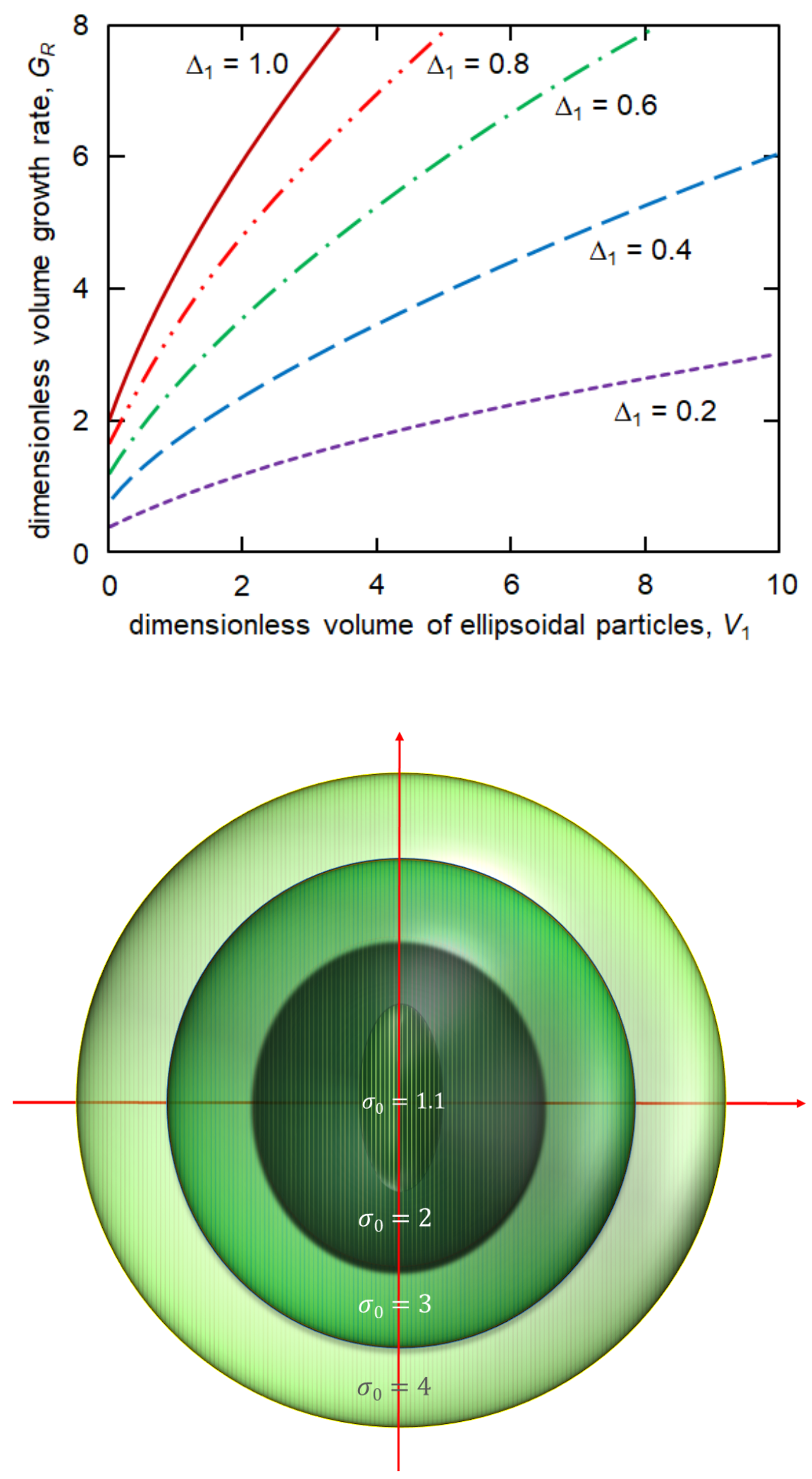